\title{
Solar forcing of winter climate variability in the northern hemisphere
}

Sarah Ineson ${ }^{1}$, Adam A. Scaife ${ }^{1}$, Jeff R. Knight ${ }^{1}$, James C. Manners ${ }^{1}$, Nick J. Dunstone $^{1}$, Lesley J. Gray ${ }^{2}$ and Joanna D. Haigh ${ }^{3}$

The influence of solar irradiance variations on Earth's surface climate has been repeatedly suggested from correlations between solar variability and meteorological variables ${ }^{1}$ which show weaker westerly winds in the winter when the sun is less active, for example at the minimum phase of the 11-year sunspot cycle $^{2,3,4}$. With some possible exceptions ${ }^{5,6}$, it has proved difficult for climate models to consistently reproduce this signal $^{7,8}$. Recent Spectral Irradiance Monitor (SIM) satellite measurements indicate that solar ultraviolet (UV) irradiance variations may be larger than previously thought ${ }^{9}$. Here we use an ocean-atmosphere climate model to confirm that, if these new observations are correct, then the model responds with a clear signal throughout the depth of the extratropical winter atmosphere, with a surface response to solar minimum resembling the negative phase of the North Atlantic or Arctic Oscillation, and of similar magnitude to the observed signal. This allows low solar activity, as observed during recent years, to drive cold winters in northern Europe and the U.S. and mild winters over southern Europe and Canada, with little direct change in globally averaged temperature. Given the quasi-regularity of the 11year solar cycle, this offers the tantalising prospect of enhanced decadal climate predictions for highly populated extratropical regions.

${ }^{1}$ Met Office Hadley Centre, FitzRoy Road, Exeter, Devon, EX1 3PB, UK. ${ }^{2}$ National Centre for Atmospheric Sciences, Department of Atmospheric, Oceanic and Planetary Physics, University of Oxford, Oxford, OX1 3PU, UK. ${ }^{3}$ Blackett Laboratory, Imperial College London, London, SW7 2AZ, UK. 
Satellite observations of solar spectral irradiance in the UV have been subject to uncertainty; the SOLSTICE and SIM instruments aboard the SORCE satellite mission (2004-present) are the first designed to achieve accurate long-term measurements of the solar irradiance variations over the entire UV range ${ }^{9}$. The $200-320 \mathrm{~nm}$ part of the UV band contributes strongly to solar heating in the middle atmosphere, largely through ozone absorption. Ozone is itself produced through the interaction between UV and oxygen, giving rise to potential positive feedback ${ }^{10}$. SORCE observations taken during the decline of solar cycle 23 reveal a remarkably strong decrease in midUV flux, some 4 to 6 times greater ${ }^{11}$ than previous spectral irradiance reconstructions ${ }^{12}$. However, prior to the SORCE mission variations at these wavelengths were poorly constrained, with measurement uncertainty exceeding the potential solar cycle variation ${ }^{13}$. Currently there is limited data (less than one solar cycle) so questions remain concerning accuracy and also applicability of the SIM data to other solar cycles ${ }^{11,14}$.

We use the SIM observations of solar variability to estimate the change in UV between the maximum and minimum of the 11-year solar cycle and impose this forcing on an ocean-troposphere-stratosphere-mesosphere climate model ${ }^{15}$. Our simulations are for 80 years of solar minimum and 80 years of solar maximum conditions. This experiment is designed to demonstrate the response in surface climate to the change in UV flux alone with a perturbation applied to the $200-320 \mathrm{~nm}$ model spectral band, and the solar irradiance flux at other wavelengths held constant. For simplicity we use monthly climatological ozone and neglect stratospheric ozone feedback ${ }^{10}$ but note that this feedback would likely enhance the effects shown below. 
In winter (December to February) the simulated and observed response at solar minimum shows substantial changes over the whole northern hemisphere (Fig.1). Model sea-level pressure increases at high northern latitudes and decreases at midlatitudes in both the Pacific and Atlantic basins corresponding to a negative Arctic Oscillation or North Atlantic Oscillation-like pattern (AO/NAO) (Fig. 1a). The observed response (Fig. 1b) also shows similarities both in structure and magnitude with the negative phase of the $\mathrm{AO} / \mathrm{NAO}$, although there is observational uncertainty in the Atlantic basin depending on the period analysed ${ }^{16,17}$. Quantifying the change in the AO sea level pressure difference between middle-latitudes and the Arctic gives a shift of $-1.2 \mathrm{hPa}$ for the model, which is in good agreement with $-1.1 \mathrm{hPa}$ for the reanalysis. For the Atlantic sector alone, the change in the NAO is $-2.4 \mathrm{hPa}$ for the model, compared to an observed change of $-4.6 \mathrm{hPa}$. (Fig 2a). Note comparatively large uncertainty in the reanalysis data due to small number of years relative to the model simulations, so that smaller, country scale anomalies can differ. Also note the symmetry in the high and low solar activity reanalysis response when compared with all years in the time series suggesting at least a degree of linearity.

Consistent with the model surface pressure pattern, decreased westerly flow in the Atlantic sector leads to anomalously cold near-surface temperatures (Fig. 1c) over north-eastern Europe and northern Asia and mild conditions further south. This is in reasonable agreement with observations (Fig. 1d) which also show negative anomalies extending over much of northern Eurasia. The regional difference in temperature between solar maximum and solar minimum for northern Europe has consistent sign and amplitude to that in observations (Fig 2b). In correspondence with the modelled decrease in the AO, we also see warming over north-eastern North America and cooling over south-eastern North America (Fig. 1c); however, no 
statistically significant changes (90\% confidence level) are seen in the reanalysis in these regions (Fig. 1d).

The observed response to decreasing solar UV irradiance begins in the upper stratosphere and lower mesosphere where satellite observations and ERA-40 reanalysis show a decrease in temperature of $1-2 \mathrm{~K}$ from solar maximum to solar minimum ${ }^{1}$. This temperature change is directly attributable to the decrease in ozone heating associated with UV irradiance, which is important at these levels ${ }^{11}$. This signal peaks in the tropics and corresponds to a relative decrease in the pole-toequator temperature gradient. This response is reproduced in our model (Fig. 3) with significant cooling of about $2 \mathrm{~K}$ near the tropical stratopause. Geostrophic balance requires that the diminished poleward temperature gradient is matched by a weak easterly wind anomaly in the sub-tropical zonal mean circulation in the upper stratosphere. This anomaly has been observed to propagate polewards and downwards during autumn and winter and to amplify as it does so, giving a midstratospheric easterly shift of $5-10 \mathrm{~ms}^{-1}$ and a weaker polar vortex in DecemberJanuary at solar minimum ${ }^{3,4}$. This mechanism is reproduced in our model. Weak subtropical easterly anomalies of $1-2 \mathrm{~ms}^{-1}$ are seen in October, which move poleward and downward from November through to February with maximum amplitude anomaly of $5-6 \mathrm{~ms}^{-1}$ in January (Fig. 4a). Similar amplitude anomalies propagate poleward and downward in the reanalysis (Fig. 4b)

Propagation and amplification of the easterly wind anomaly is associated with altered planetary wave activity ${ }^{18,4}$. Eliassen-Palm (EP) flux divergence simulated at solar minimum indicates a greater easterly forcing (i.e. an increase in wave driving) of the polar night jet in the shear region below the maximum zonal wind anomaly (Fig. 5). 
This leads to a local deceleration and downward propagation of the easterly anomaly. Large scale wave forcing is therefore driving the development of the response in our model, in agreement with observational analyses ${ }^{4}$ and earlier modelling studies ${ }^{6}$ Following this winter signal, during February and March a westerly anomaly develops at high altitude and moves polewards and downwards, in both the reanalysis and model (albeit weaker in the model). Stratospheric oscillations are known to occur even in the presence of steady tropospheric planetary wave forcing ${ }^{19}$ and these late winter westerly wind anomalies appear to be associated with a similar "Polar Jet Oscillation”4, with the initial easterly phase of the oscillation being determined by solar forcing as described above.

Signals in the lower stratosphere communicate a response throughout the depth of the troposphere, particularly in the storm track regions (Fig. 1) and while the mechanism is still subject to debate it involves a dynamically balanced tropospheric response to the stratospheric circulation change above, and occurs as a robust feature of experiments where the stratosphere is perturbed ${ }^{20}$. Altered development of baroclinic instability in the troposphere ${ }^{21}$, or a feedback between the propagation of synopticscale eddies and the eddy-driven jet ${ }^{22}$ may also be important.

Our experiment confirms a 'top-down', stratosphere to troposphere, pathway for the high latitude response to recent observed solar variability with an altered westerly jet. The AO/NAO like pattern and changes in atmospheric circulation that emerge from the model resemble the previous observed estimates of the effects of solar variability not only in pattern and evolution but also in amplitude through the autumn and winter seasons. Climate models, including those with comprehensive upper atmosphere physics $^{7,8}$, have typically been inconsistent in simulating the observed extra-tropical 
response to the 11-year solar cycle, with the model response often weak or not significant. Our experiments suggest that underestimation of the UV component of the solar variability could provide a plausible explanation. This idea is supported by early experiments where larger but arbitrary imposed changes in UV flux in a numerical model reproduced the observed polewards and downwards evolution through internal dynamics $^{23}$. The establishment of a large enough upper stratosphere meridional temperature gradient is crucial to this mechanism and we note that other recent studies show the model response in the equatorial upper stratosphere to be substantially larger with SIM data than with an earlier solar variability reconstruction ${ }^{11,24 .}$

Other studies have discussed possible 'bottom-up' influences on surface climate through changes in surface radiative effects ${ }^{25}$, but we exclude this possibility in our runs as there are no imposed changes to incoming radiation at visible wavelengths. Our experiment demonstrates that the observed extratropical circulation response can be driven from the new observational estimates of UV variations alone. Likewise our experiment can say little about links between solar variability and global mean temperature change ${ }^{24,11}$. We have also ignored possible modulation by the quasibiennial oscillation (QBO) suggested in some observational ${ }^{2}$ and modelling ${ }^{7}$ studies, $^{2}$ although our model does produce a spontaneous QBO.

The average of recent winters (2008/9, 2009/10 and 2010/11) shows cold conditions over northern Europe and the USA and mild conditions over Canada and the Mediterranean associated with anomalously low and even record low values of the NAO. This period also had easterly anomalies in the lower stratosphere. Given our modelling result, these cold winters were likely exacerbated by the recent prolonged and anomalously low solar minimum ${ }^{26}$. On decadal timescales the increase in the 
NAO from the 1960s to 1990s, itself known to be strongly connected to changes in winter stratospheric circulation ${ }^{20}$ may also be partly explained by the upward trend in solar activity evident in the open solar flux record ${ }^{26}$. There could also be confirmation of a leading role for the 'top-down' influence of solar variability on surface climate during periods of prolonged low solar activity such as the Maunder Minimum ${ }^{27}$ if the UV variations used here also apply to longer timescales.

The solar effect presented here contributes a substantial fraction of typical year-toyear variations in near surface circulation, with shifts of up to $50 \%$ of the interannual variability (Fig. 1a,b). This represents a substantial shift in the probability distribution for regional winter climate and a potentially useful source of predictability. Solar variability is therefore an important factor in determining the likelihood of similar winters in future. However, mid-latitude climate variability depends on many factors, not least internal variability, and forecast models which simulate all the relevant drivers are needed to estimate the range of possible winter conditions.

Our result has important implications for regional climate prediction in the northern extratropics. Fluctuations in the NAO often dominate the seasonal and decadal winter climate but its predictability on seasonal and decadal timescales is $l o w^{28,29}$. If the recent satellite data are typical of the variation in UV fluxes in other solar cycles ${ }^{14}$ then our results suggest shifts in the NAO of a sizeable fraction of the interannual variability. Given the quasi-regularity of the 11-year solar cycle, our results therefore suggest significant decadal predictability in the NAO.

\section{METHODS SUMMARY}


Climate model. We use a version of the Met Office Hadley Centre general circulation model, similar to HadGEM3 revision1.1 ${ }^{15}$. The atmosphere resolution is $1.875^{\circ}$ longitude by $1.25^{\circ}$ latitude with 85 vertical levels providing a well resolved middle atmosphere with an upper boundary at $85 \mathrm{~km}$. The model has an internally generated QBO. Incoming shortwave radiation is split into six bands. The UV band, 200-320nm, has 5 coefficients to describe absorption across the band. The ocean employs a nominal $1^{\circ}$ tripolar horizontal grid with latitudinal grid refinement in the tropics such that the latitude spacing decreases to $1 / 3^{\circ}$ on the equator and there are 42 levels in the vertical.

UV radiation difference between solar maximum and minimum. Measurements ${ }^{9}$ from the SIM instrument (2004-2007) are extrapolated in time to represent the full solar cycle amplitude. We estimate the difference between solar maximum and minimum in the $200-320 \mathrm{~nm}$ band to be $1.2 \mathrm{Wm}^{-2}$, a $4 \%$ change, and distribute this evenly across the UV band. No changes are made in other bands.

Experiment design. An 80 year control simulation represents solar minimum. A 20member ensemble of 5-year simulations, with initial conditions taken at regular intervals from the control and using the SIM-based perturbation, represents solar maximum. Our analysis uses the final 4 years of each member giving a total of 80 years. Figures show the difference between solar minimum and maximum.

Reanalysis data. ERA-40/ERA-Interim reanalysis data ${ }^{30}$ from 1957 to 2010 are segregated into winters with open solar magnetic flux ${ }^{17,26}$ in the top and bottom thirds of the values in the ERA period. Figures show the difference between the composites of low-solar and high-solar winters. Winters following major tropical volcanic eruptions (1963-4, 1964-5, 1965-6, 1982-3, 1983-4, 1984-5, 1991-2, 1992-3, 1993-4) are excluded from the analysis. 
Statistics. Model statistical significance is tested using a Students t-test with the null hypothesis that the difference in means between solar minimum and maximum is not significantly different from zero. Reanalysis significance is assessed using data from 1000 pairs of randomly selected subsets of the ERA-period years of the same size as used in the high and low open solar flux index composites. The distribution of the differences in the means of the subsets in each pair was used to diagnose the likelihood of the derived solar signal arising by chance. 1-tailed tests were used.

\section{References}

1. Gray, L. J. et al. Solar influences on climate. Rev. Geophys., 48, RG4001 (2010).

2. Labitzke, K. Sunspots, the QBO, and the stratospheric temperature in the north polar region, Geophys. Res. Lett. 14, 535-537 (1987).

3. Kodera, K. On the origin and nature of the interannual variability of the winter stratospheric circulation in the northern hemisphere. J. Geophys. Res. 100(D7), 14,077-14,087 (1995).

4. Kodera, K. \& Kuroda Y. Dynamical response to the solar cycle, J. Geophys. Res. 107(D24), 4749 (2002).

5. Matthes, K., Kuroda, Y., Kodera, K. \& Langematz, U. Transfer of the solar signal from the stratosphere to the troposphere: Northern winter. J. Geophys. Res., 111, D06108 (2006). 
6. Shindell, D. T., Schmidt, G. A., Miller, R. L. \& Rind, D. Northern Hemisphere winter climate response to greenhouse gas, ozone, solar, and volcanic forcing, $J$. Geophys. Res. 106, 7193-7210 (2001).

7. Schmidt, H., Brasseur, G. P. \& Giorgetta, M. A. Solar cycle signal in a general circulation and chemistry model with internally generated quasi-biennial oscillation. $J$. Geophys. Res. 115, D00I14 (2010).

8. Tsutsui, J., Nishizawa, K. \& Sassi, F. Response of the middle atmosphere to the 11-year solar cycle simulated with the Whole Atmosphere Community Climate Model. J. Geophys. Res. 114, D02111 (2009).

9. Harder, J. W., Fontenla, J. M., Pilewskie, P., Richard, E. C. \& Woods T. N. Trends in solar spectral irradiance variability in the visible and infrared. Geophys. Res. Lett. 36, L07801 (2009).

10. Haigh, J. D. A GCM study of climate change in response to the 11-year solar cycle. Quart. J. Roy. Meteor. Soc, 125, 871-892 (1999).

11. Haigh, J. D., Winning, A., Toumi, R. \& Harder, J. W. An influence of solar spectral variations on radiative forcing of climate. Nature, 467, 696-699 (2010).

12. Lean, J. Evolution of the Sun's Spectral Irradiance since the Maunder Minimum, Geophys. Res. Lett. 27, 2425-2428 (2000). 
13. Krivova, N. A., Solanki, S. K.,Wenzler, T. \& Podlipnik B. Reconstruction of solar UV irradiance since 1974. J. Geophys. Res. 114, D00I04 (2009).

14. Garcia, R. R. Nature 467, 668-669 (2010).

15. Hewitt, H. T., Copsey, D., Culverwell, I. D., Harris, C. M., Hill, R. S. R., Keen, A. B., McLaren, A. J. \& Hunke, E. C. Design and implementation of the infrastructure of HadGEM3: the next-generation Met Office climate modelling system. Geosci. Model Dev. 4, 223-253 (2011).

16. Roy, I. \& Haigh, J. D. Solar cycle signals in sea level pressure and sea surface temperature. Atmos. Chem. Phys. 10, 3147-3153 (2010).

17. Woollings, T., Lockwood, M., Masato, G., Bell, C. \& Gray, L. Enhanced signature of solar variability in Eurasian winter climate. Geophys. Res. Lett. 37, L20805 (2010).

18. Hines, C. O. A Possible Mechanism for the Production of Sun-Weather Correlations. J. Atmos. Sci. 31, 589-591 (1974).

19. Scaife, A. A. \& James, I. N. Response of the stratosphere to interannual variability of tropospheric planetary waves. Quart. J. Roy. Meteor. Soc. 126, 275-297 (2000). 
20. Scaife, A. A., Knight, J. R., Vallis, G. K. \& Folland, C. K. A stratospheric influence on the winter NAO and North Atlantic surface climate. Geophys. Res. Lett. 32, L18715 (2005).

21. Wittman, M. A. H., Polvani, L. M., Scott, R. K. \& Charlton, A. J. Stratospheric influence on baroclinic lifecycles and its connection to the Arctic Oscillation. Geophys. Res. Lett. 31, L16113 (2004).

22. Simpson, I. R., Blackburn, M. \& Haigh J. D. The role of eddies in driving the tropospheric response to stratospheric heating perturbations, J. Atmos. Sci. 66, 13471365 (2009).

23. Kodera, K., Yamazaki, K., Chiba M. \& Shibata K. Downward propagation of upper stratospheric mean zonal wind perturbation to the troposphere. Geophys. Res. Lett. 17(9), 1263-1266 (1990).

24. Cahalan, R. F., Wen, G., Harder, J. W. \& Pilewskie, P. Temperature responses to spectral solar variability on decadal time scales. Geophys. Res. Lett., 37, L07705 (2010).

25. Meehl, G. A., Arblaster, J. M., Matthes, K., Sassi, F. \& H. van Loon, H. Amplifying the Pacific Climate System Response to a Small 11-Year Solar Cycle Forcing. Science 325 (5944), 1114-1118 (2009).

26. Lockwood, M., Harrison, R.G., Woollings, T. \& Solanki, S. Are cold winters in Europe associated with low solar activity? Environ. Res. Lett. 5, 024001 (2010). 
27. Shindell, D. T., Schmidt, G. A., Mann, M. E., Rind, D. \& Waple, A. Solar forcing of regional climate change during the Maunder minimum. Science 294, 2149-2152 (2001).

28. Arribas, A., Glover, M., Maidens, A., Peterson, K., Gordon, M., MacLachlan ,C., Graham, R., Fereday, D., Camp, J., Scaife, A. A, Xavier, P., McLean, P., Colman, A. \& Cusack, S. The GloSea4 ensemble prediction system for seasonal forecasting. Mon. Wea. Rev. 139, 1891-1910 (2011).

29. Kushnir, Y., Robinson, W. A., Chang, P. \& Robertson, A. W. The physical basis for predicting Atlantic sector seasonal-to-interannual climate variability. J. Climate, 19, 5949-5970 (2006).

30. Uppala, S. M., et al. The ERA-40 re-analysis. Q. J. R. Meteorol. Soc. 131(612), 2961-3012 (2005).

Acknowledgements This work was supported by the Joint DECC/Defra Met Office Hadley Centre Climate Programme (GA01101) (Met Office Hadley Centre authors), by the UK Natural Environmental Research Council (NERC) through their National Centre for Atmospheric Research (NCAS) Climate program (L. J. G) and by the NERC SOLCLI consortium grant (J. D. H.). We thank Drew Shindell for constructive comments on the manuscript. The ERA-40 and ERA-Interim data is provided by ECMWF from their data server and we are grateful to Tim Woollings for categorising past years with respect to observed solar variability. 
Author contributions S.I. ran the model experiments. A.A.S. and S.I. analysed the results. J.C.M. advised on adapting the radiation code. J.R.K. analysed the ERA reanalysis data and advised on statistical methods. A.A.S, S.I., J.C.M. and N.J.D. wrote the paper. All authors planned the experiment, discussed the results and commented on the manuscript.

Author information Reprints and permissions information is available at www.nature.com/reprints . The authors declare no competing financial interests. Correspondence and requests for materials should be addressed to S.I. (sarah.ineson@metoffice.gov.uk) 

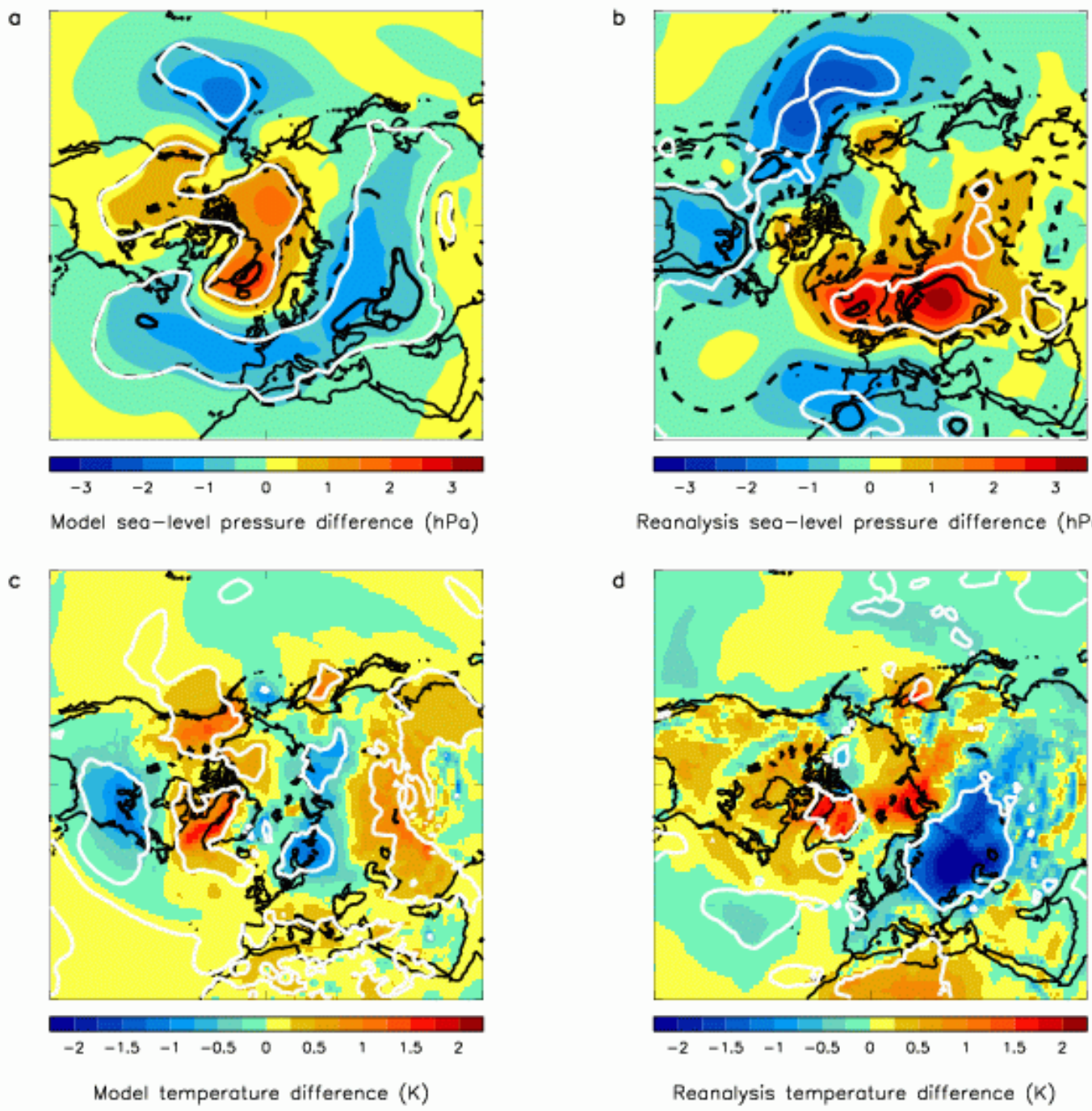

Reanalysis seo-level pressure difference ( $\mathrm{hPo}$ )

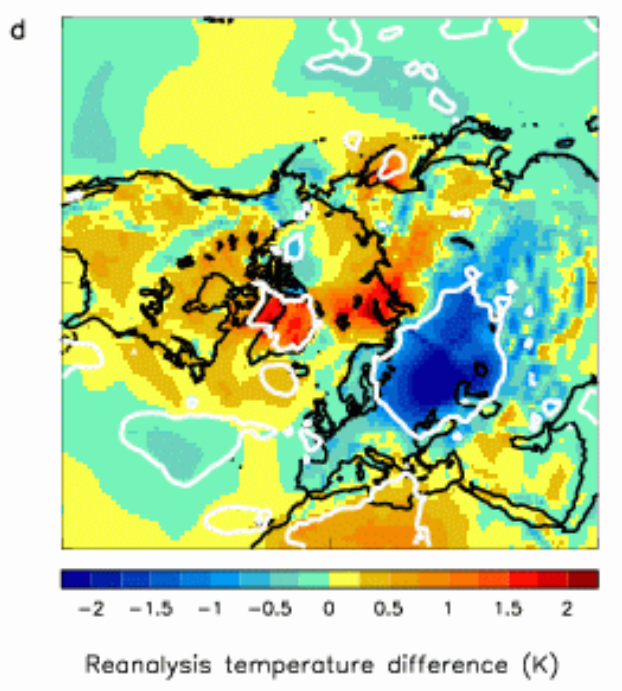

Figure 1. Difference in winter surface climate for solar minimum minus solar maximum. Sea-level pressure difference (hPa) for the model (a) and ERA-40/ERAInterim reanalysis (b). Near-surface temperature difference (K) for the model (c) and reanalysis (d). Differences are for December to February mean fields. Dashed (solid) black contours show the sea-level pressure difference relative to the interannual standard deviation at 25 (50) \%. Solid white contours indicate significance at the 95\% confidence level for the model (a, c) and 90\% for reanalyses (b, d). 
a

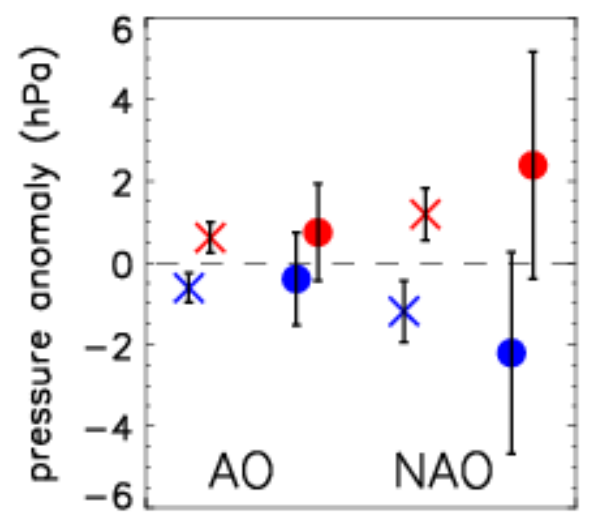

b

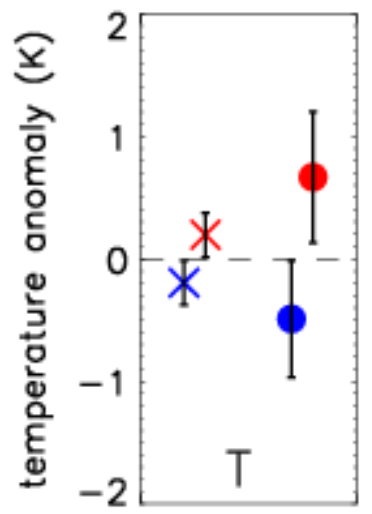

Figure 2. Agreement between modelled and observed surface climate response.

Winter (December to February) composite anomalies for solar minimum (blue) and solar maximum (red) for model (crosses) and reanalyses (circles). (a) 'AO' sea-level pressure difference $(\mathrm{hPa})$ between middle-latitude $\left(30-55^{\circ} \mathrm{N}\right)$ and Arctic-latitude (65$\left.90^{\circ} \mathrm{N}\right)$ bands, 'NAO' sea-level pressure difference (hPa) between Azores and Iceland, and (b) ' $\mathrm{T}$ ' near-surface temperature $(\mathrm{K})$ for Northern European region $\left(0-60^{\circ} \mathrm{E}, 50\right.$ $\left.70^{\circ} \mathrm{N}\right)$. Vertical lines show the standard error. 


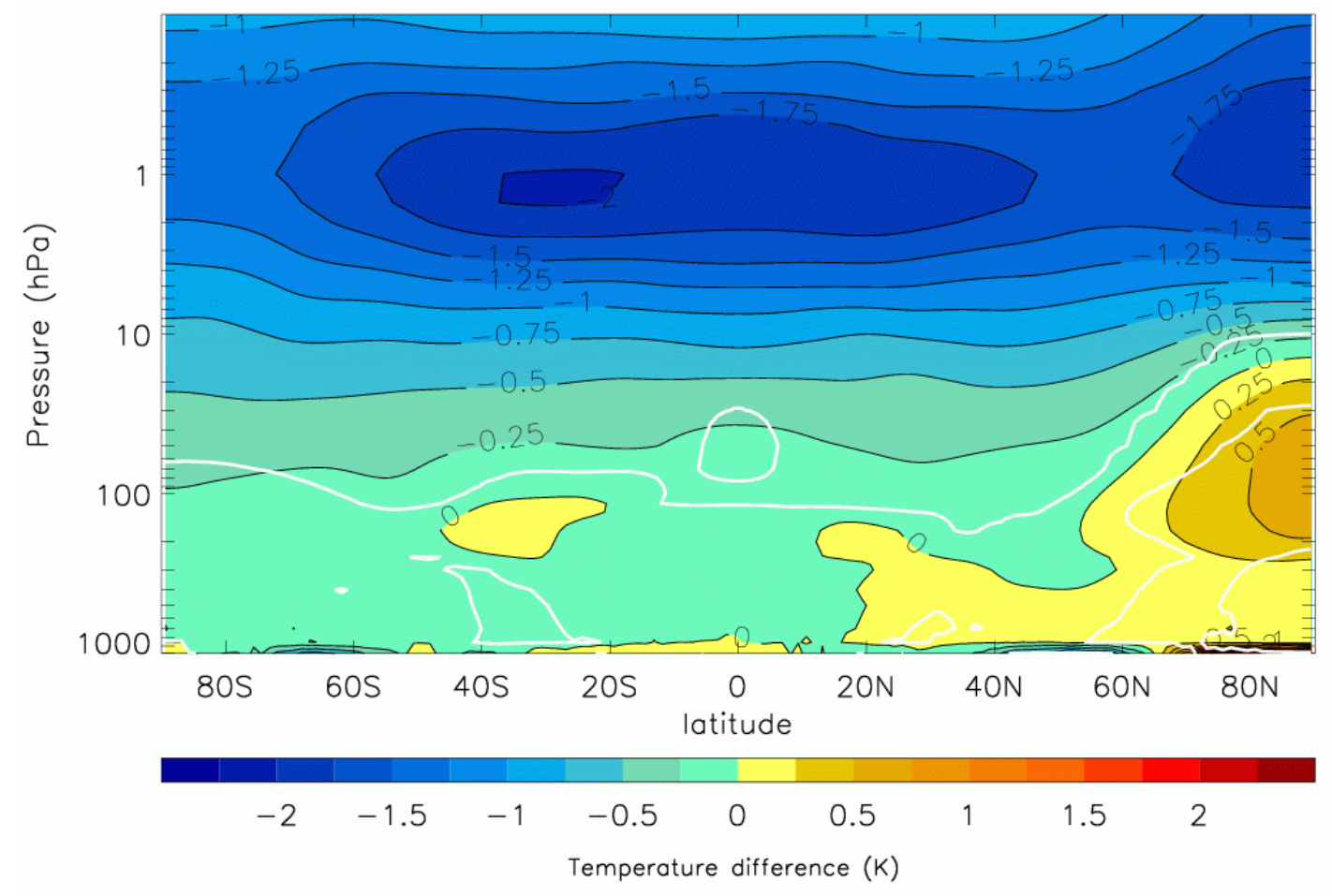

Figure 3. Modelled zonal mean temperature difference for solar minimum minus

solar maximum. Annual zonal mean temperature difference (K). Solid white contour indicates significance at the 95\% confidence level. 

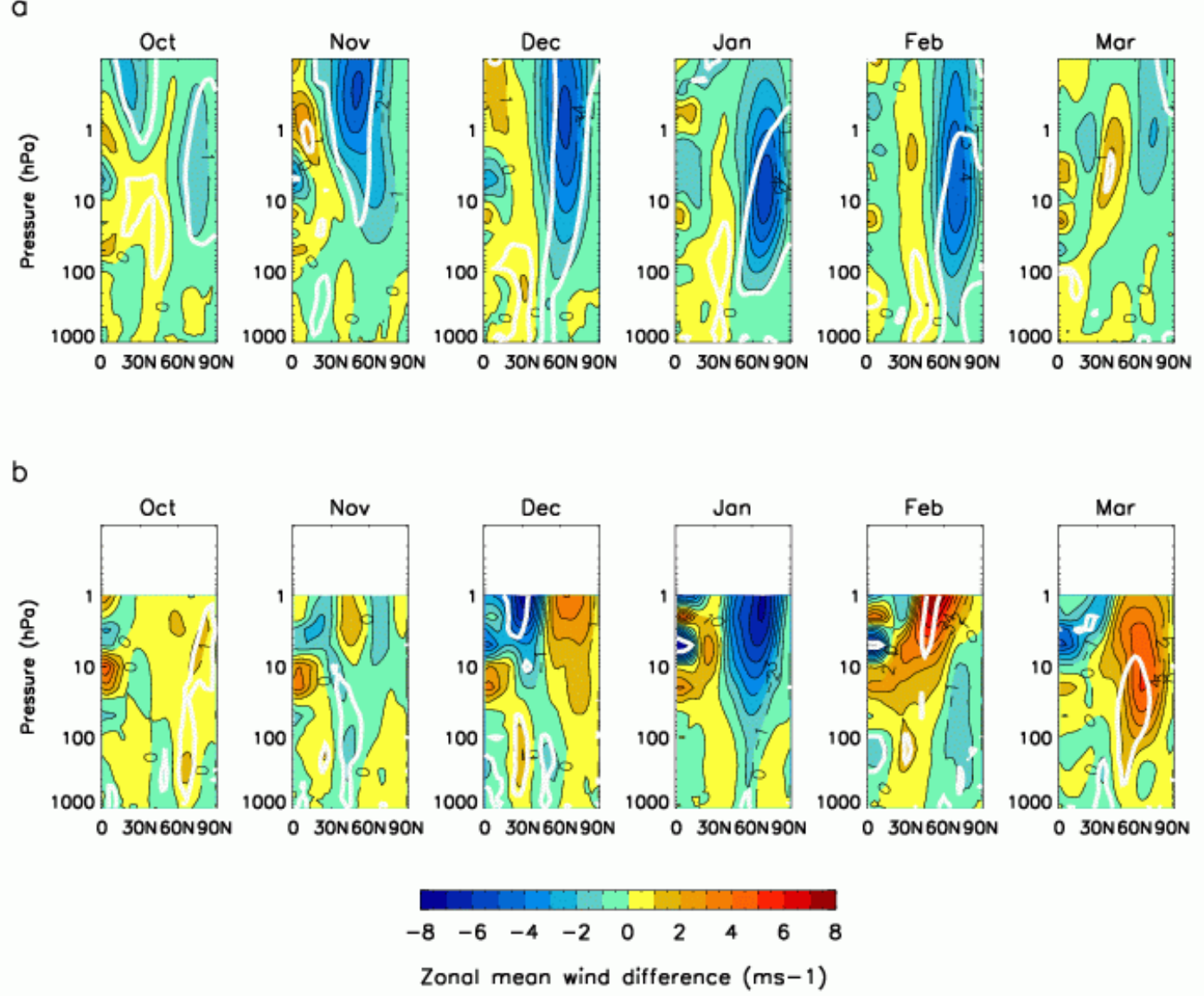

Figure 4. Poleward and downward progression of the solar climate signal.

Composite monthly zonal mean zonal wind $\left(\mathrm{ms}^{-1}\right)$ for the difference between solar minimum and maximum for October to March in model (a) and reanalysis (b). Solid white contours indicate significance at the 95\% confidence level for the model (a) and $90 \%$ for reanalysis (b). 


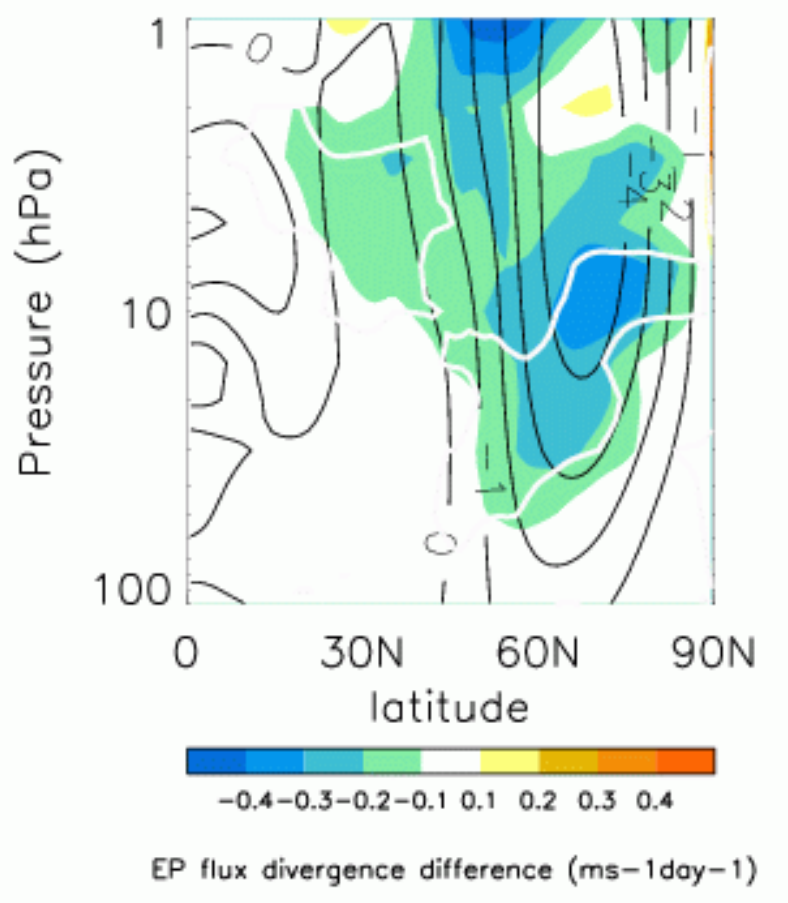

Figure 5. Modelled large scale wave driving of the solar climate response. Zonal mean zonal wind $\left(\mathrm{ms}^{-1}\right)$ (contours) and EP flux divergence $\left(\mathrm{ms}^{-1} \mathrm{day}^{-1}\right)$ (colours) for the difference between solar minimum and maximum. Differences are for JanuaryFebruary means. EP flux divergence has been scaled by the inverse of the pressure. Solid white contours indicate significance at the 95\% confidence level. 